\title{
Demographic history, genetic structure and gene flow in a steppe-associated raptor species
}

\author{
Jesus T Garcia ${ }^{1 *}$, Fernando Alda ${ }^{1}$, Julien Terraube ${ }^{1,2}$, François Mougeot $^{3}$, Audrey Sternalski ${ }^{1,4}$, Vincent Bretagnolle $^{4}$ \\ and Beatriz Arroyo ${ }^{1}$
}

\begin{abstract}
Background: Environmental preferences and past climatic changes may determine the length of time during which a species range has contracted or expanded from refugia, thereby influencing levels of genetic diversification. Connectivity among populations of steppe-associated taxa might have been maximal during the long glacial periods, and interrupted only during the shorter interglacial phases, potentially resulting in low levels of genetic differentiation among populations. We investigated this hypothesis by exploring patterns of genetic diversity, past demography and gene flow in a raptor species characteristic of steppes, the Montagu's harrier (Circus pygargus), using mitochondrial DNA data from 13 breeding populations and two wintering populations.

Results: Consistent with our hypothesis, Montagu's harrier has relatively low genetic variation at the mitochondrial DNA. The highest levels of genetic diversity were found in coastal Spain, France and central Asia. These areas, which were open landscapes during the Holocene, may have acted as refugia when most of the European continent was covered by forests. We found significant genetic differentiation between two population groups, at the SW and NE parts of the species' range. Two events of past population growth were detected, and occurred ca. 7500-5500 and ca. 3500-1000 years BP in the SW and NE part of the range respectively. These events were likely associated with vegetation shifts caused by climate and human-induced changes during the Holocene.

Conclusions: The relative genetic homogeneity observed across populations of this steppe raptor may be explained by a short isolation time, relatively recent population expansions and a relaxed philopatry. We highlight the importance of considering the consequence of isolation and colonization processes in order to better understand the evolutionary history of steppe species.
\end{abstract}

\section{Background}

Contemporary patterns of genetic diversity and population structure reflect not only current patterns of genetic exchange but also past dispersal processes and levels of gene flow among populations during historical climatic events $[1,2]$. In many species inhabiting temperate zones, climate-vegetation feedbacks during the Pleistocene caused range contractions to lower latitudes followed by range expansions during interglacial periods $[2,3]$, which in turn promoted much of the diversification observed today. However, not all species responded similarly to these past climatic events. Species-specific responses to these changes are the result of a complex

\footnotetext{
* Correspondence: jesus.ggonzalez@uclm.es

'Instituto de Investigación en Recursos Cinegéticos (IREC) (CSIC-UCLM-JCCM). Ronda de Toledo s/n, E-13005 Ciudad Real, Spain Full list of author information is available at the end of the article
}

interplay between the behavioral, physiological and ecological characteristics of the species, including their biogeographic origin, habitat preferences and dispersal capabilities [4]. Climatic conditions prevailing at different time periods strongly influenced the extent of each habitat type in the past, which should in turn influence the length of time during which a species underwent isolation or range expansion and, consequently, the opportunities for genetic diversification [3,5]. For example, species inhabiting arctic or boreal areas seem to have experienced range expansions during the long glacial periods, but remained isolated during the short interglacial ones [6-8], leading to a pattern of contemporary genetic structure different from that of species inhabiting temperate areas. The phylogeography of temperate and arctic species is rather well studied. In contrast, the phylogeography of steppe species, which are
C Biomed Central 
biogeographically in-between the temperate and arcticboreal fauna, remains scarcely known $[4,9]$. During the glacial periods, many of these species were widely distributed throughout the periglacial steppes of the northern hemisphere. For these steppe species, gene flow at large geographic scales might have been interrupted by the postglacial retreat and reduction of steppe vegetation during the short interglacial phases. Therefore, the amount of time spent in isolation, and the resulting genetic differentiation, should be smaller for steppe species as compared with temperate ones. The distribution of steppe species during the glacial periods is well documented by fossil evidence [10-12], but the genetic evidence is still relatively poor [9,13-15]. In addition, steppe-like ecosystems (including natural and agricultural landscapes) are probably amongst the most altered habitats nowadays, due to human pressure and rapid changes in land use [16]. Consequently, the abundance and distribution range of many steppe/farmland species has greatly declined in recent years [17-22].

The Montagu's harrier Circus pygargus is perhaps the best example of raptor species specialized in such steppe habitats, which has also adapted well to farmland habitats $[23,24]$. This species is widely but patchily distributed across the Palearctic region and undertakes longdistance migrations [25] (Figure 1). Migration studies based on satellite tracking and ringing recoveries show that European and Asian breeding populations follow different migratory pathways and overwinter in different continents (Figure 1). Central Asian populations, where it is accepted that the stronghold of the species occurs (ca. 25,000-30,000 pairs [26]), migrate along an eastern route and overwinter in the Indian subcontinent (Pakistan and India [27]). European populations migrate through the Mediterranean peninsulas and overwinter in the Sahel belt from western to eastern Africa [28-30]. To date, no specific study has evaluated the genetic structure and gene flow among populations of this species or closely related ones.

We used molecular analyses to evaluate levels of genetic diversity and connectivity among Montagu's harrier breeding populations. We collected genetic material from across the whole breeding range (Spain to Kazakhstan) and from two overwintering populations (located in western Africa and in the Indian sub-continent). With this information, we analyzed historical demographic patterns, in order to better understand how past climatic dynamics may have affected the species and shaped its current distribution and population genetic structuring. Specifically, our aims were: first, to evaluate the genetic diversity of Montagu's harrier populations and analyze different scenarios that may explain the observed genetic structure (according to physical barriers, overwintering areas or current breeding

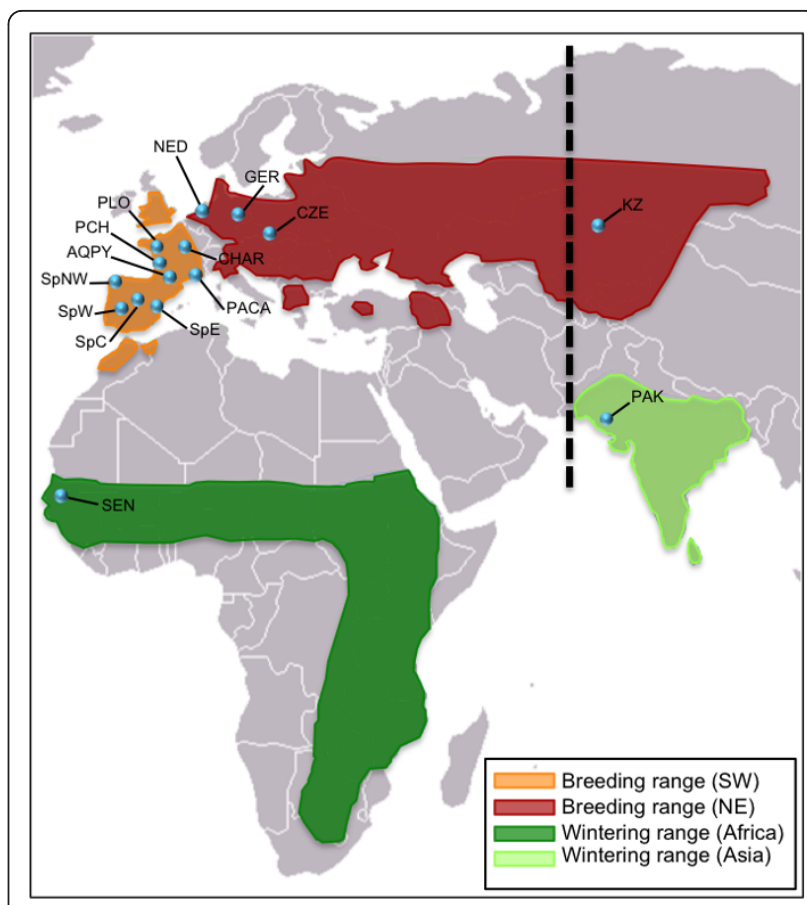

Figure 1 Map showing the geographic range of breeding populations of Montagu's harrier (redrawn from[86]) and sampling localities used in this study. Orange and red colors correspond to breeding grounds; the large lump in the breeding distribution in the old USSR reflects a lack of detailed knowledge on their distribution rather than a continuous range. The figure shows the separations between the two main distribution areas within the range. Green colors correspond to wintering grounds. Locality codes are as indicated in Table 1. The doted black line shows the location of the intercontinental migratory divide proposed by Moreau [27] to split the breeding populations wintering in the Indian sub-continent from those wintering in Africa

distribution); second, to investigate past demographic changes in the species, and patterns of gene flow between genetically structured populations, looking for evidence of asymmetrical exchanges between these. Finally, we discuss the implications of these results for the understanding of the patterns shaping the phylogeographic structure of the fauna associated with steppe ecosystems.

\section{Results}

We sequenced a total of 1063 bp of t-RNA Trp and ND2 and 714 bp of COI genes from all samples ( $\mathrm{n}=$ 284), which were collapsed into 36 and 13 haplotypes, respectively (Additional file 1 ). The concatenated data set (1777 bp) yielded 51 different haplotypes defined by 35 polymorphic sites. Overall, gene and nucleotide diversities were $\mathrm{Hd}=0.663(\mathrm{SD}, 0.032)$ and $\pi=0.0008$ (SD, 0.00007), respectively (Table 1 ). Most of the observed genetic variability was in the form of single nucleotide substitutions. The mean number of pairwise 
Table 1 Sample sizes and genetic characteristics.

\begin{tabular}{|c|c|c|c|c|c|c|c|c|}
\hline Country & Region & Abrev. & $\mathrm{n}$ & $\mathrm{nH}$ & $\mathrm{Hd}( \pm \mathrm{SD})$ & $\pi( \pm \mathrm{SD})$ & $D$ & $F_{S}$ \\
\hline \multicolumn{9}{|l|}{ Breeding range } \\
\hline Spain & Extremadura & SpW & 38 & 8 & $0.3798 \pm 0.100$ & $0.000469 \pm 0.00038$ & $-2.26^{*}$ & $-3.28^{*}$ \\
\hline Spain & Toledo, Ciudad Real & $\mathrm{SpC}$ & 12 & 4 & $0.5606 \pm 0.150$ & $0.000639 \pm 0.00050$ & $-1.53^{*}$ & 0.62 \\
\hline Spain & Castellón & SpE & 22 & 6 & $0.6797 \pm 0.095$ & $0.000672 \pm 0.00041$ & -1.19 & -0.96 \\
\hline Spain & Galicia & SpNW & 20 & 8 & $0.7421 \pm 0.096$ & $0.000758 \pm 0.00055$ & $-1.82^{*}$ & $-3.71^{*}$ \\
\hline France & Provence-Alps-Cote Azur & PACA & 19 & 7 & $0.8246 \pm 0.064$ & $0.000987 \pm 0.00067$ & -0.92 & -0.24 \\
\hline France & Pays Loire & PLO & 6 & 4 & $0.8667 \pm 0.125$ & $0.001651 \pm 0.00116$ & -0.49 & 1.36 \\
\hline France & Poitou-Charente & $\mathrm{PCH}$ & 51 & 13 & $0.6894 \pm 0.070$ & $0.000954 \pm 0.00063$ & $-1.55^{*}$ & -3.17 \\
\hline France & Champagne-Ardenne & CHAR & 21 & 8 & $0.6762 \pm 0.111$ & $0.000820 \pm 0.00058$ & $-1.84^{*}$ & -0.36 \\
\hline France & Aquitaine-Pyrenees & AQPY & 10 & 5 & $0.7556 \pm 0.129$ & $0.000538 \pm 0.00045$ & -1.11 & -0.33 \\
\hline The Netherlands & Oldenzaal & NED & 12 & 4 & $0.4545 \pm 0.170$ & $0.000963 \pm 0.00068$ & -0.84 & 0.32 \\
\hline Germany & Lower Saxony & GER & 6 & 2 & $0.3333 \pm 0.215$ & $0.000188 \pm 0.00025$ & -0.93 & -0.00 \\
\hline Czech Republic & Vysočyna & CZE & 13 & 4 & $0.6026 \pm 0.130$ & $0.000909 \pm 0.00065$ & 0.45 & 0.32 \\
\hline Kazakhstan & Naurzum, Kostanay & KZ & 32 & 8 & $0.6875 \pm 0.077$ & $0.000845 \pm 0.00058$ & -0.60 & -0.61 \\
\hline \multicolumn{9}{|l|}{ Wintering areas } \\
\hline Senegal & Nianing & SEN & 10 & 2 & $0.3556 \pm 0.155$ & $0.000200 \pm 0.00024$ & & \\
\hline Pakistan & Hyderabad & PAK & 12 & 8 & $0.9242 \pm 0.057$ & $0.001808 \pm 0.00113$ & & \\
\hline \multicolumn{9}{|l|}{ Geographic origin } \\
\hline SW & & & & & & & $-2.27^{*}$ & $-28.5^{*}$ \\
\hline NE & & & & & & & -1.18 & $-10.2^{*}$ \\
\hline Pooled & & & 284 & 51 & $0.663 \pm 0.032$ & $0.000826 \pm 0.00007$ & & \\
\hline
\end{tabular}

Summary of the number of samples $(\mathrm{n})$, number of haplotypes $(\mathrm{nH})$, haplotype diversity $(\mathrm{Hd})$ and nucleotide diversity $(\pi)$ for the concatenated data set in each sampling locality. Tajima's $(D)$, Fu's $\left(F_{S}\right)$ measure departure of the data from neutrality. The significance (at the $P=0.05$ level) of these statistics is indicated with an asterisk $\left(^{*}\right)$ for each breeding population and for the SW and NE demes (see text). SD = standard deviation.

nucleotide differences for all samples (concatenated data set) was 1.47 (SD, 0.94).

French populations showed the highest nucleotide and haplotype diversities when considering each gene partition separately (ND2 and COI, results not shown) or the concatenated data set (Table 1). Haplotype diversities were also high in the coastal regions of Spain (Galicia and Castellón). The lowest haplotype diversities were found in populations from Germany and Netherlands (Table 1). Regarding the two wintering sites, levels of genetic diversity were greater in Pakistan than in Senegal (Table 1).

\section{Genetic structure}

The two phylogenetic methods used (Maximum likelihood and Bayesian inference) were largely consistent in the (lack of) relationships recovered. Despite the broad geographic sampling (Figure 1), there was little phylogenetic structure and low branch support (Figure 2). The haplotype network revealed no major branching events (Figure 2), although two groups of haplotypes could be differentiated. The first group was distributed around haplotype Hap2, which was observed in 57\% of individuals and had a widespread geographical distribution. The other haplotypes were generally site-specific and occurred at low frequencies. The second group consisted mostly of rare haplotypes from all geographic regions except Senegal. In general, haplotypes specific to certain geographic regions did not form monophyletic groups, but appeared to be randomly distributed across the network (Figure 2).

Differences among Montagu's harrier populations accounted for a significant $5.15 \%$ of total molecular variance (Table 2). Hierarchical analyses testing for differences between populations in relation to their geographic origin showed low but significant differentiation among groups of populations located in the southwestern (SW) vs. north-eastern (NE) parts of the breeding range (scenario 1), with low levels of genetic variation among populations within each group. In contrast, the structure scenarios based on geographic barriers (scenario 2) or based on an intercontinental migratory divide (scenario 3) revealed no significant among-group differences (Table 2). The $\Phi_{\mathrm{CT}}$ estimate obtained for scenario 3 was similar to that obtained for scenario 1 , and close to significance (Table 2). This suggested some structuring in relation to the migratory divide, although the higher and significant value of $\Phi_{\mathrm{ST}}$ indicated larger heterogeneity among populations within groups than in scenario 1. Including samples from wintering areas might affect, to some extent, these results, but the exclusion of these wintering samples also entails the loss of important genetic information. We repeated these analyses without including the samples from the two overwinter sites, and results were qualitatively the same. 


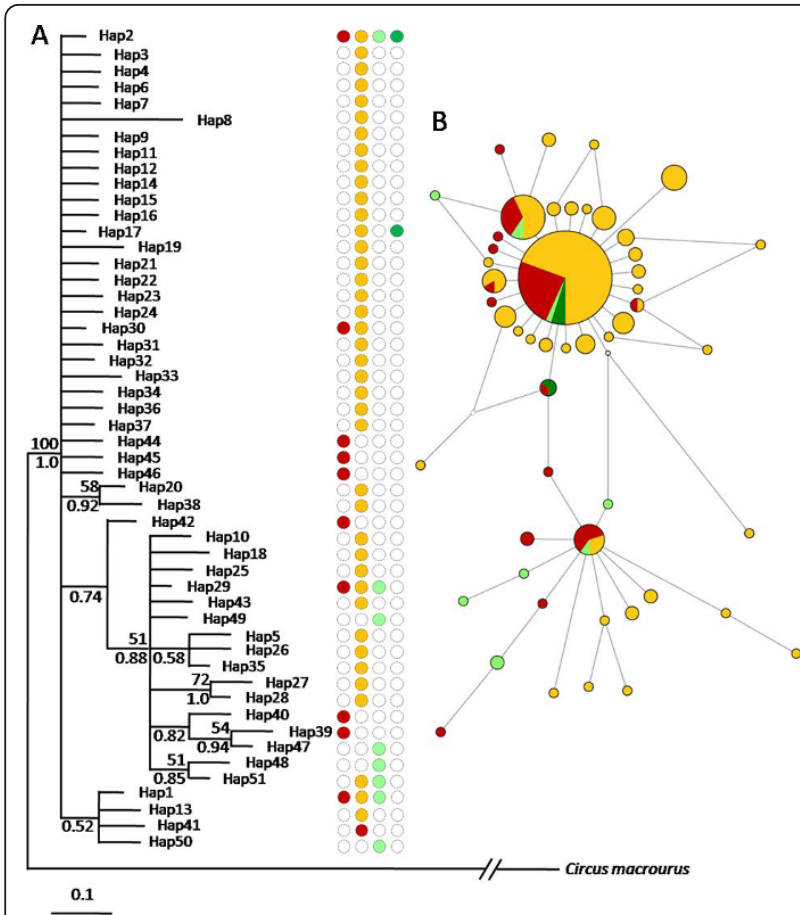

Figure 2 Phylogenetic relationships among mitochondrial DNA haplotypes. A) Maximum-likelihood (ML) tree of Circus pygargus based on mtDNA sequences. Numbers above branches indicate ML bootstrap values (1000 replicates) and numbers below branches indicate Bl posterior probabilities. Only bipartitions with bootstrap or posterior probability values above 50 and 0.5 , respectively, are shown. B) Median-joining haplotype network based on the mtDNA concatenated data set. Circle size is proportional to haplotype frequency and connecting lines are proportional to mutation steps between haplotypes. White circles represent hypothetical intermediate or un-sampled haplotypes. Each color refers to one geographic area (orange: SW populations; red: NE populations; dark green: Senegal; light green: Pakistan).

Overall, 27 out of 105 pairwise $\Phi_{\mathrm{ST}}$ comparisons between populations were significant. Comparisons involving Pakistan were significant in all but four cases (Table 3). Differences were smallest between Pakistan and Czech Republic $\left(\Phi_{\mathrm{ST}}=0.037\right)$ and largest between Pakistan and western Spain (PAK-SpW: $\Phi_{\mathrm{ST}}=0.324$ ). In contrast, comparisons involving Senegal were significant only with central France (PLO) and Pakistan (SENPLO: $\Phi_{\mathrm{ST}}=0.159$, and SEN-PAK: $\left.\Phi_{\mathrm{ST}}=0.224\right)$. Considering only breeding populations, eastern Spain $(\mathrm{SpE})$ showed the highest number of significant pairwise comparisons (seven out of 12), while the largest differentiation among populations was found between western Spain (SpW) and central France (PLO) (SpW-PLO: $\Phi_{\mathrm{ST}}$ $=0.216)$. Finally, the correlation between population pairwise $\Phi_{\mathrm{ST}}$ values and their geographical distances was not significant (Mantel test, $\mathrm{r}=-0.06, \mathrm{p}=0.70$ ).

\section{Demographic analyses}

The whole breeding population exhibited significantly negative values for both Tajima's $D(D=-2.28, \mathrm{p}=$ $0.0023)$ and Fu's $F_{S}\left(F_{S}=-68.94, \mathrm{p}<0.001\right)$, suggesting that the overall population size has fluctuated in the past. The majority of $D$ and $F_{S}$ values were negative for most of the studied populations, but Fu's $F_{S}$ rejected neutrality $(\mathrm{p}<0.02)$ in only two breeding populations, whereas Tajima's $D$ rejected neutrality $(\mathrm{p}<0.05)$ in five populations (Table 1). We further considered the two groups of populations (from the SW and NE regions) whose genetic structure differed according to AMOVA analysis (see above). Each group of populations also showed negative $D$ and $F_{S}$ values that were all significant except for the Tajima's $D$ of the NE group (Table 1).

The effective population sizes and demographic trends estimated by the Bayesian Skyline Plot (BSP) analysis indicated recent population size increases in both regions (SW and NE). However, the overall increase was much less marked for the SW populations, which showed a roughly linear increase during the second part of the Holocene. Based on a range of mutation rates from 0.02 to $0.055 \mathrm{~s} / \mathrm{s} / \mathrm{Myr}$, population growth started at approximately 7500 years before present (BP) in SW and 4000 years BP in NE (Figure 3). The time to the

\section{Table 2 AMOVA summary.}

\begin{tabular}{|c|c|c|c|c|c|}
\hline \multicolumn{6}{|l|}{$\begin{array}{l}\text { Concatenated } \\
\text { data }\end{array}$} \\
\hline Scenario & Grouping & Populations in group & $\begin{array}{l}\text { Between } \\
\text { group } \\
\Phi_{\mathrm{CT}} \\
\end{array}$ & $\begin{array}{l}\text { Between } \\
\text { population within } \\
\text { group } \Phi_{S T}\end{array}$ & $\begin{array}{l}\text { Within } \\
\text { population } \\
\Phi_{\mid \mathrm{S}}\end{array}$ \\
\hline $\begin{array}{l}\text { 1. Geographic } \\
\text { distribution }\end{array}$ & Southwestern vs. Northeastern & $\begin{array}{l}\text { (SpW, SpC, SpNW, SpE, PACA, PLO, PCH, AQPY, } \\
\text { CHAR) vs. (NED, GER, CZE, KZ, PAK) }\end{array}$ & $\begin{array}{l}4.23 \\
(0.0009)\end{array}$ & $3.21(0.011)$ & $\begin{array}{l}92.56 \\
(0.000)\end{array}$ \\
\hline $\begin{array}{l}\text { 2. Geographic } \\
\text { barriers }\end{array}$ & $\begin{array}{l}\text { Spain vs. Western Europe vs. } \\
\text { Eastern Europe vs. central Asian }\end{array}$ & $\begin{array}{l}\text { (SpW, SpC, SpNW, SpE) vs. (PACA, PLO, PCH, } \\
\text { AQPY, CHAR, NED, GER) vs. (CZE) vs. (KZ, PAK) }\end{array}$ & $2.48(0.114)$ & $3.42(0.007)$ & $\begin{array}{l}94.10 \\
(0.000)\end{array}$ \\
\hline $\begin{array}{l}\text { 3. Migratory } \\
\text { divide }\end{array}$ & Africa vs. India & $\begin{array}{l}\text { (SpW, SpC, SpNW, SpE, PACA, PLO, PCH, AQPY, } \\
\text { CHAR, NED, GER, CZE, SEN) vs. (KZ, PAK) }\end{array}$ & $4.55(0.087)$ & $3.66(0.0009)$ & $\begin{array}{l}91.78 \\
(0.000)\end{array}$ \\
\hline No grouping & & & & $5.15(0.000)$ & $\begin{array}{l}94.85 \\
(0.000)\end{array}$ \\
\hline
\end{tabular}

Results of AMOVA (concatenated data, Tamura and Nei; gamma $=0.2487$ ) testing for differences between Montagu's harrier populations and geographic areas. The analysis partitions out total molecular variance into different components, and statistical significance is obtained by randomization after 5000 permutations. Significant differences between groups are shown in bold. 
Table 3 Between-population genetic differentiation in Circus pygargus.

\begin{tabular}{|c|c|c|c|c|c|c|c|c|c|c|c|c|c|c|c|}
\hline & SpW & $\mathrm{SpC}$ & SpE & SpNW & PACA & PLO & $\mathrm{PCH}$ & CHAR & AQPY & NED & GER & CZE & KZ & SEN & PAK \\
\hline SpW & - & & * & & & * & & * & & & & * & * & & $* * *$ \\
\hline $\mathrm{SpC}$ & 0.0115 & - & & & & & & & & & & & & & \\
\hline SpE & 0.0346 & 0.0066 & - & & * & $* *$ & * & $* * *$ & & $*$ & & $* *$ & $*$ & & \\
\hline SpNW & 0.0022 & -0.0098 & 0.0157 & - & & * & & & & & & & & & \\
\hline PACA & 0.0353 & 0.0144 & 0.0386 & -0.0056 & - & & & & & & & & & & \\
\hline PLO & 0.2161 & 0.1091 & 0.1646 & 0.1312 & 0.0897 & - & & & & & & & $*$ & * & \\
\hline $\mathrm{PCH}$ & 0.0156 & -0.0050 & 0.0395 & -0.0009 & 0.0137 & 0.0667 & - & & & & & & & & \\
\hline CHAR & 0.0314 & 0.0079 & 0.0491 & 0.0280 & 0.0268 & 0.0781 & 0.0148 & - & & & & $*$ & & & ** \\
\hline AQPY & 0.0233 & 0.0330 & 0.0387 & 0.0305 & 0.0132 & 0.1028 & 0.0236 & -0.0270 & - & & & * & & & $* *$ \\
\hline NED & 0.0436 & -0.0051 & 0.0657 & 0.0181 & 0.0143 & 0.0648 & -0.0049 & 0.0279 & 0.0537 & - & & & & & \\
\hline GER & -0.0680 & -0.0239 & -0.0470 & -0.0816 & -0.0629 & 0.1068 & -0.0453 & -0.0308 & -0.0000 & 0.0000 & - & & & & \\
\hline CZE & 0.1290 & 0.0445 & 0.1278 & 0.0546 & 0.0286 & 0.0786 & 0.0209 & 0.0891 & 0.1350 & -0.0183 & 0.0787 & - & & & \\
\hline KZ & 0.0386 & 0.0131 & 0.0559 & -0.0030 & -0.0077 & 0.1209 & 0.0051 & 0.0518 & 0.0651 & 0.0018 & -0.0399 & -0.0037 & - & & \\
\hline SEN & -0.0030 & -0.0044 & 0.0195 & -0.0177 & 0.0109 & 0.1596 & -0.0182 & 0.0052 & 0.0635 & 0.0035 & 0.0585 & 0.0656 & 0.0087 & - & \\
\hline PAK & 0.3241 & 0.1891 & 0.2781 & 0.2068 & 0.1541 & 0.1246 & 0.1928 & 0.2415 & 0.2503 & 0.0660 & 0.1826 & 0.0370 & 0.1451 & 0.2240 & \\
\hline
\end{tabular}

Below the diagonal, pairwise $\Phi_{\mathrm{ST}}$ values (based on Tamura and Nei distances between haplotypes; gamma $=0.248$ ). Above the diagonal, $\mathrm{p}$-values for significant $\Phi_{\text {ST }}$ values obtained after 5000 permutations $\left(* \mathrm{p}<0.05 ;{ }^{* *} \mathrm{p}<0.01,{ }^{* * *} \mathrm{p}<0.001\right)$.

most recent common ancestor (TMRCA) was estimated at 21,000 (40,000-6000 95\% highest posterior density, HPD) and 35,000 years BP (61,000-13,000 95\% HPD) for SW and NE groups, respectively. Independent runs of IMa gave similar results, and plots of parameter trends indicated sufficient mixing among chains. The estimated effective population size for the SW region

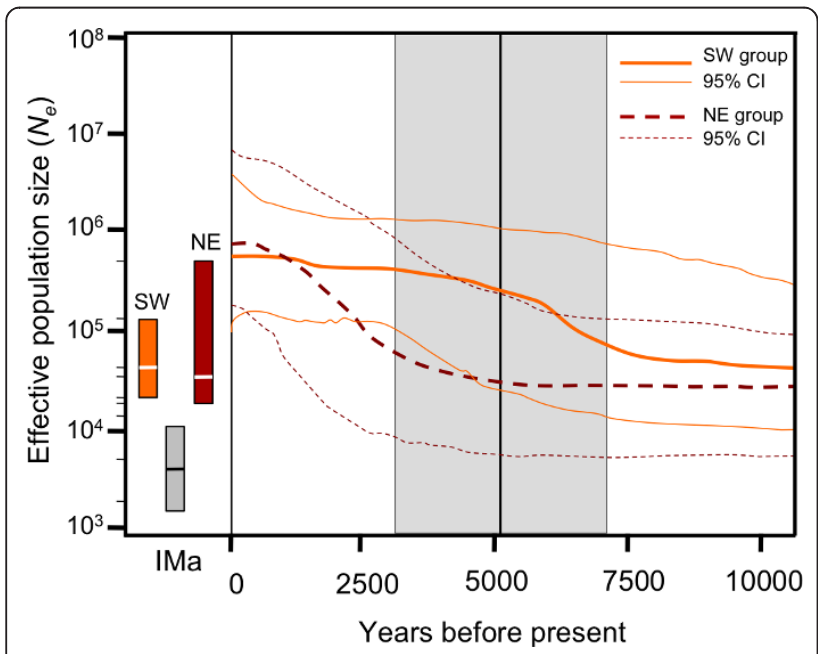

Figure 3 Bayesian skyline plot generated with BEAST v1.5.4. and effective population size $(\mathrm{Ne})$ and time estimates under IMa. The solid red lines are the median and 95\% confidence intervals $(\mathrm{Cl})$ estimates for SW populations while dotted blue lines for NE populations. The shaded box in the centre of the figure represents the mean and $95 \% \mathrm{Cl}$ for the time of population splitting estimated by IMa for SW and NE groups of Montagu's harriers. Boxes represent $95 \% \mathrm{Cl}$ for the $\mathrm{N}_{e}$ estimated by IMa with SW and NE groups and the ancestral population in grey. Lines inside the boxes represent the peak of the marginal distribution values. $\left(\right.$ peak $\theta_{S W}=75.18,90 \%$ HPD $=41.4-123.1$; Figure 3$)$ was similar to that of the NE region (peak $\theta_{N E}$ at 63.45, $90 \%$ HPD $=16.5$ - 397.0; Figure 3), despite larger HPD in NE than in SW group. Both descendant populations had effective population sizes that were over one order of magnitude larger than the ancestral population $\left(\theta_{A}\right)$, which peaked at $10.28(90 \% \mathrm{HPD}=2.82-17.57)$. Based on these values of $\theta$, both populations appeared to have grown substantially following divergence. The average estimate for the scaled splitting time was $t=0.37$ (90\% $\mathrm{HPD}=0.22-0.50$; Figure 3), suggesting that the NE and SW groups of populations started to diverge about 5200 years BP $(7100$ - 3100 years BP considering the range of mutation rates used). The gene flow estimate from SW into NE was low $(m=0.66,90 \%$ HPD $=$ $0.0035-4.12)$, and close to null from NE into SW ( $m=$ $0.0035,90 \%$ HPD $=0.0035-2.88$ ). Conversion of these values of $m$ resulted in an estimated number of migrants of approximately 0.004 females per generation from NE to SW populations (one female every 250 generations), and 22 females per generation from SW to NE populations. However, the associated error to these estimates was large $\left(90 \% \mathrm{HPD}_{\mathrm{SW}}=0.1-108 ; 90 \% \mathrm{HPD}_{\mathrm{NE}}=0.1-\right.$ 130 female migrants per generation).

\section{Discussion}

\section{Genetic diversity of Montagu's harrier}

Overall, we found little mitochondrial DNA variation among populations of Montagu's harrier throughout the breeding range. Although variability was low, we nevertheless found significant differentiation between southwestern and northeastern populations. In contrast to the low among-population variability, our study revealed a relatively high degree of genetic diversity at the mtDNA 
for this species as compared with those found in other sympatric raptor species. These other raptors often show much less polymorphism, even when using genetic markers that are more variable than the mitochondrial control region (examples from vultures in [31]). Some of these studies have associated these low levels of genetic diversity with recent decreases in population sizes, like for instance in the Spanish imperial eagle Aquila adalberti [32], Red kite Milvus milvus [33], Bonelli's eagle Hieraaetus fasciatus [34], White-tailed eagle Haliaeetus albicilla [35], and Bearded vulture Gypaetus barbatus [36]. The mtDNA diversity of the Montagu's harrier is not consistent with a recent population decline, unlike in these other studied raptor species. However, genetic diversity is rarely homogeneously distributed within a species range, because it reflects the long-term effects of historical events [2]. Despite relatively small sample sizes for some localities, we were able to identify two strongholds of genetic diversity for the Montagu's harrier, one in the western part of the range (France and coastal Spain), and another in central Asia. This coincides with the distribution of open vegetation in the mid Holocene, which was restricted to the Iberian Peninsula and coastal areas of France and to central Asia [37-39] suggesting that these areas may have acted as refuges for the species at a time when most of Europe was covered by dense forest [40]. Fossil records confirm the presence of Montagu's harriers in the western region from the Pleistocene through the Holocene [12]. However, our lack of sampling locations in East Asia prevents us from pinpointing primary areas of Montagu's harrier diversity in this region. Additional sampling would help to establish if the diversity found in Kazakhstan reflects higher levels of diversity in the Asian steppes, as suggested by the high diversity found in the wintering grounds of Asian breeding populations (PAK) compared to their west European counterparts (SEN).

The haplotype network consisted of two distinct, but closely related, lineages (Figure 2) that could also be indicative of two refugia or nuclei from where the species expanded. The existence in Eurasia of a western and an eastern or central refuge area has been proposed for other bird species $[31,35,41,42]$, and the highest values of genetic diversity observed in France and in Kazakhstan would be consistent with such scenario. However, we found no relationship between lineages and their geographic origin (Figure 2). This could be a consequence of the low divergence between the two haplotype groups, suggesting a short time of isolation for these populations. This would be expected for a steppe bird whose habitat was potentially reduced during a short period within the present interglacial period, rather than during the longer glacial periods, as postulated for temperate species [4]. During the Pleistocene, the duration of the steppe-favorable period would have allowed harriers to fully expand their range, leading to a high connectivity between different demes. This could have erased any phylogeographic signal, as is commonly observed in species characterized by a high dispersal capability and exploiting a wide ecological niche [35].

\section{Population structure and phylogeography}

In many animal species, the patterns of genetic differentiation and gene flow are highly influenced by the geographical characteristics of the places they inhabit and by their migratory behavior. However, in the Montagu's harrier, neither the geographical barriers (mountain ranges) nor the intercontinental migratory divide (populations wintering in Africa or in the Indian sub-continent) represented significant barriers against gene flow. Interestingly, the levels of genetic differentiation between populations were unrelated to the geographical distances separating these populations. This could be explained by the long-distance migration behavior of the species. Western European breeding birds (Spain, France) winter primarily in west Africa (Senegal, Mauritania and Mali $[30,43])$, while central and eastern-European harriers (the Netherlands, Czech Republic and Germany in this study) winter further east (Niger, Nigeria and Chad [29]). Montagu's harriers may perform winter movements following outbreaks of locusts and grasshoppers (their main food in winter) [29]. Additionally, wind conditions may influence the migratory routes, particularly in spring [44]. Some individuals might thus migrate through a different route upon their return (spring) migration, and finally disperse and breed far away from their natal place. This could explain the lack of significant genetic structure between populations a priori assigned to different overwintering areas. This hypothesis of different migration routes between spring and autumn is supported by ring recoveries [28] and counts of migratory birds in the central Mediterranean [45], although satellite telemetry-based studies (conducted on a limited number of individuals) indicate that most birds follow the same route in spring and autumn migrations [46]. While the correlation between genetic and geographical distances for all populations was nonsignificant, the AMOVA test gave statistical evidence for a differentiation between the SW and NE populations (although only $5 \%$ of the genetic variation was explained by this partition). In other words, location of the breeding areas may be important when explaining the genetic structure of populations at a broad scale, whereas geographical distance between populations is not. These observations, together with the low number of significant comparisons between pairs of populations, points to dispersal as a major factor preventing genetic differentiation within these two regions of the breeding range 
of Montagu's harriers. Such a relaxed philopatric behavior has indeed been described for the species [47].

\section{Demographic history}

Our results strongly support a recent population expansion as an important cause of the relative homogeneity across populations. Such expansion is indicated by the shallow phylogenetic tree and by the star-like haplotype network (Figure 2). The genetic signature observed in the two main Montagu's harrier groups of populations (SW vs. NE) is consistent with the occurrence of postglacial demographic expansions during the second half of the Holocene, as evidenced by the BSP analyses. These revealed two events of population growth that occurred first in the SW (ca. 7500-5500 years BP), and later in the NE part of the range (ca. 3500 to 1000 years BP; Figure 3). The effective population size increases also appeared more pronounced in the NE than in the SW populations (Figure 3). Furthermore, these two groups of populations diverged around 5200 years ago, between the two waves of population growth. This pattern may be explained by regional differences in the impact of both climate changes and human activity on vegetation during the Holocene. Ample evidence support that during the last glacial maximum $(37,000$ 16,000 years BP), the tundra-steppe vegetation was widespread from France to the Bering strait (e.g. [48]). Therefore, according to the preference of Montagu's harrier for open steppe-like landscapes, the species would have been widely distributed throughout Eurasia. Then, during the following interglacial period at the beginning of the Holocene, about 10,000 years ago, this vast system disappeared almost completely as a consequence of the quick expansion of temperate forests (in Europe) and taigas (in Asia) from their ice-Age refugia [49]. This probably led to strong range contraction and population declines in steppe-associated communities. Unfortunately, based on our data set, coalescent times go back only 10,000 years, therefore changes in population size before that date (e.g. after the last glacial maximum ca.18,000 to 10,000 years BP) cannot be inferred.

Although this particular issue has received little attention so far (phylogeographic studies of steppe species are still scarce), our data are consistent with the recent idea of interglacial refugia, which proposes that, in addition to the traditional high-latitude refugia of boreal species, cryptic refugia might have existed in other areas in the south during the interglacials $[4,9]$. In fact, climate reconstructions based on pollen records have shown that, during the Holocene, the climate was neither stable nor uniform across Eurasia [50-52]. Therefore, the occurrence of these cryptic refugia, and consequently the severity of climate change impacts on species, might have been qualitatively different among regions of Europe and Asia [53]. During the Holocene, steppe biomes occurred recurrently $[54,55]$, coinciding with major dry events leading up to glacial conditions at different time intervals: 11.000-9.500 years BP, 8000-7000 years BP and 4000-3000 years BP $[54,56]$. More recently, an overall more arid period has been described in Eurasia during the last 4500 years (e.g. $[39,57])$. This, together with the increasing anthropogenic landscape transformations from 4000-3000 years ago (e.g. clearance of forested areas, cultivation, cattle grazing $[49,58,59])$, may have provided, either naturally or artificially, new steppe-like habitats for many species to colonize $[60,61]$. This temporal pattern is consistent with our data and could explain the recent population growths detected in both groups. The earlier and slower population growth detected in the SW group might have been associated with an increase in the extent of suitable open habitats after a major Holocene climate change dated around 8000 years BP [62]. In contrast, the existence of large steppe extensions in the East together with a lack of evidence supporting the aforementioned cooling event 8000 years ago in this region [62] would explain the lack of synchronous expansions of Montagu's harrier population groups. Additionally, studies on pollen spectra have clearly indicated that around 3000 and 1000-500 years BP steppe biomes were relatively abundant in the eastern part of the range (e.g. [54]), thus agreeing with the fast population growth observed in the northeastern populations of Montagu's harrier around that period of time (Figure 3).

\section{Conclusions}

Our results point to a short isolation time, relatively recent population expansions and relaxed philopatry as the main factors determining the relative genetic homogeneity observed across populations of a steppe-associated raptor species. In contrast to the traditional view $[3,63]$, our findings do not support an important role of southern Mediterranean peninsulas for extensive colonization of formerly treeless northern regions. In our case, rather than a source of postglacial colonization, the Iberian Peninsula would represent an area of postglacial refuge for steppe fauna. This finding implies that the population genetic models of glacial isolation and postglacial colonization developed for temperate taxa might have limited applications for steppe species. However, there is still little evidence for the direct effect of past climatic events on the genetic variability and phylogeographic structure in steppe-associated fauna at a regional or continental scale (but see $[9,13]$ ). Our study has added new insights into the knowledge of how genetic variation in steppe-associated taxa has been influenced by late Pleistocene and Holocene climatic changes. Future research should include a comparative approach, 
which would allow the comparison of phylogeographic patterns in a wider range of co-distributed species. This would contribute to a better understanding of how glacial cycles have sculpted the genetic variation of steppeassociated taxa in Eurasia.

\section{Methods}

\section{Sampling}

We analyzed genetic material from 284 Montagu's harrier specimens collected in 13 localities across the species' breeding range, from Spain to Kazakhstan, and from two wintering areas (Senegal, and Pakistan) (Table 1). Samples were grouped a priori according to sampling locality, and these groups were considered as populations for genetic analyses (see Table 1 and Figure 1). All samples are contemporary (collected in 1999-2009) and consisted of blood $(n=204)$ or feathers $(n=80)$. When nestlings were used as a source for DNA $(<10 \%$ of samples) we used only one chick per brood to avoid pseudo-replication of mitochondrial haplotypes.

\section{DNA isolation, polymerase chain reaction (PCR) and sequencing}

Blood samples were digested $(8 \mathrm{~h})$ in $250 \mu \mathrm{L}$ SET buffer in the presence of SDS $(2 \%)$ and proteinase $\mathrm{K}(10 \mathrm{ng} / \mu \mathrm{L})$. Feathers were processed like blood samples but increasing proteinase $\mathrm{K}(20 \mathrm{ng} / \mu \mathrm{L})$ and time of digestion $(16 \mathrm{~h})$. Total genomic DNA was extracted using standard $\mathrm{NH}_{4}$ Ac protocol. Purified DNA was diluted to a working concentration of $25 \mathrm{ng} / \mu \mathrm{L}$. We amplified two mitochondrial regions including partial tRNA-Trp and NADH dehydrogenase subunit 2 (ND2) and a portion of the cytochrome oxidase subunit I (COI) via polymerase chain reaction (PCR). Primers L5216-H5766 and L5758-H6313 were used for the amplification of ND2 gene [65], and BirdF1 and BirdR1 [66] for the COI fragment. PCR reactions were run using the following parameters: denaturation at $95^{\circ} \mathrm{C}$ for $3 \mathrm{~min}$, followed by 35 cycles of $94{ }^{\circ} \mathrm{C}$ for $60 \mathrm{~s}, 54^{\circ} \mathrm{C}$ for $60 \mathrm{~s}$, and $72{ }^{\circ} \mathrm{C}$ for $60 \mathrm{~s}$, and a final extension at $72^{\circ} \mathrm{C}$ for $5 \mathrm{~min}$. PCRs contained approximately $25 \mathrm{ng}$ of template DNA, $1 \times$ PCR buffer (Biotools), $0.25 \mathrm{mM}$ of each dNTP, $0.3 \mu \mathrm{M}$ of each primer, $2 \mathrm{mM} \mathrm{MgCl} 2$, and $0.5 \mathrm{U}$ of Taq DNA polymerase (Biotools) in a total volume of $10 \mu \mathrm{L}$.

PCR-products were purified with Exonuclease I and Shrimp Alkaline Phosphatase enzymatic reactions (United States Biochemical). Purified reactions were sequenced in an ABI 3130 automated sequencer (Applied Biosystems) using dye-terminator chemistry (BigDye kit 3.1, Applied Biosystems) with the same primers used for PCR. All sequences are accessible at GenBank (Additional File 1).

\section{Genetic diversity and population structure analyses}

We edited and aligned DNA sequences using Bioedit [67] and Clustal W [68]. Arlequin 3.5.1.2 [69] was used to determine the number of haplotypes and variable sites, and to calculate genetic diversity in each population (at the haplotype and nucleotide levels). Genetic differentiation between populations was tested using pairwise $\Phi_{\mathrm{ST}}$ comparisons for each mtDNA region and for the concatenated data set, using a Tamura-Nei evolutionary model [70], as this is the closest model to the one inferred for our data set in Modeltest 3.7 [71]. The significance of pairwise $\Phi_{\text {ST }}$ comparisons was given by a $P$ value calculated using 10,000 random permutation tests; $p$-values were further adjusted according to sequential Bonferroni corrections for multiple tests [72]. Evidence for population genetic structure was assessed using an analysis of molecular variance (AMOVA) as implemented in Arlequin 3.5.1.2. Tamura-Nei distances plus gamma correction $(\alpha=0.2487)$ were selected for the concatenated data set. We first examined overall differences among populations (i.e. sampling localities without grouping) and then we determined the contributions of different grouping scenarios to the partitioning of genetic variation in the dataset. For this purpose, we tested three hypothetical scenarios (Table 2): (1) differentiation explained by the species current geographic distribution. We compared south-western (SW) vs. north-eastern populations (NE), which represent currently samples from a large and continuous breeding area (SW) and smaller populations with a more overall patchy distribution, both separated by a gap in the overall breeding distribution range ([73]; see Figure 1); (2) differentiation between populations separated by geographic barriers (i.e. mountain ranges: Pyrenees/ Alps/Urals) as potential barriers to gene flow. For this, we compared Spanish, Western-central European, Eastern European, and Asian populations; (3) differentiation in relation to the intercontinental migratory divide (i.e. differences between populations wintering in Africa vs. those wintering in the Indian subcontinent).

Since all Montagu's harrier overwintering in the Indian subcontinent come from Asian breeding populations [27], winter samples from the Indian sub-continent (Pakistan) were included into the NE population group (in scenario 1) or into the Asian population group (in scenarios 2 and 3). Likewise, in scenario 3, samples from Senegal were pooled into the group of Montagu's harrier populations wintering in Africa. In all cases, we repeated these analyses without including samples from the two overwinter sites.

A pattern of isolation-by-distance was explicitly tested using Mantel tests to compare pairwise geographic and genetic distances between populations. These were statistically tested using linearized pairwise differentiation indexes $\left(\Phi_{\mathrm{ST}} /\left(1-\Phi_{\mathrm{ST}}\right)\right.$ in Arlequin 3.5.1.2. The statistical significance of correlations between distance matrices 
was obtained from 5,000 random permutations of matrix elements.

\section{Phylogenetic analysis}

Phylogenetic relationships of Montagu's harrier were reconstructed by examining mtDNA sequence variation in all samples. The best-fit evolutionary model for the concatenated data set was determined using the Akaike information criterion implemented in Modeltest 3.7. A Maximum-Likelihood (ML) tree was built using a heuristic search starting from a neighbour-joining tree and a tree bisection reconnection (TBR) algorithm for branch swapping, with random addition of sequences in PAUP* 4.0 [74]. The statistical support for internal branches of the tree was estimated by 1,000 bootstrap replicates. This model was also used to carry out Bayesian inference (BI) of phylogeny as implemented in MrBayes v3.1.2 [75], simulating four simultaneous Monte Carlo Markov Chains (MCMC) for $5 \times 10^{6}$ generations each. The first 250,000 generations were discarded as burn-in. Bayesian posterior probabilities were obtained to assess the robustness of the BI trees. Trees were rooted with one sequence of $C$. macrourus, which was used as outgroup (Additional File 1).

We also represented the genealogical relationships of all the analyzed samples of $C$. pygargus with a haplotype network calculated using the median-joining algorithm [76] in NETWORK $4.5 \mathrm{http}: / /$ www.fluxus-engineering. com.

\section{Demographic history}

Signatures of demographic changes or selection in the recent history of C. pygargus, considering a model of mutation-drift equilibrium, were addressed using analyses based on different coalescent approaches. Firstly, we tested the data against a neutral Wright-Fisher model using Fu's Fs [77] and Tajima's $D$ [78], which aim to identify an excess of recent single nucleotide substitution caused by population growth, bottleneck, or background selection. We performed this test in Arlequin 3.5.1.2. Significance of the statistics was determined by 1000 coalescent simulations of the neutral model, where $P$ must be less than 0.02 to be significant due to the non-normal distribution of the Fs statistic [77]. Secondly, because departures from neutrality are often caused by changes in effective population size, we generated a Bayesian Skyline Plot (BSP) to explore changes in genetic diversity occurring at a certain time period within a given genealogy using MCMC based sampling, and to generate the posterior distribution of the effective population size at that time $\left(N_{e}\right)$ [79]. We used a strict molecular clock and a range of substitution rates estimated for other bird species (0.02-0.055 substitutions/ site/Myr; $[13,80,81])$. Four independent analyses were performed in BEAST v1.5.4 [79] and ran for $4 \times 10^{7}$ generations with a sampling frequency of 1000 steps. Convergence was assessed using Tracer v1.5 [82] and uncertainty in parameter estimates reflected in values of the $95 \%$ highest posterior density (HPD). We also used BEAST v1.5.4 to estimate the time to the most recent common ancestor (TMRCA) for each group of sequences analyzed as well as for the complete data set.

Thirdly, because AMOVA tests revealed genetic breaks between geographical regions (SW vs. NE, scenario 1), we used the program IMa [83] to test the hypothesis of a shared-history scenario of isolation with migration for the SW and NE population groups. This model assumes that an ancestral population of constant size and population parameter $\theta_{\mathrm{A}}$ separated into two populations (SW and NE) at time $T$, to simultaneously determine (1) time since divergence $(t),(2)$ effective population sizes of each population $\left(\theta_{S W}\right.$ and $\left.\theta_{N E}\right)$ and the ancestral population $\left(\theta_{\mathrm{A}}\right)$ at time of split, and (3) immigration rates $\left(m_{S W}\right.$ and $\left.m_{N E}\right)$. We ran three replicate runs with a random seed to initiate each run. In all analyses, we used at least 20 Markovcoupled chains with a geometric heating scheme, a burn-in of 200,000 steps, and run until the effective sample sizes (ESS; see [83]) for each parameter were at least 500. To ensure proper chain mixing and parameter convergence, all parameter trend lines were visually inspected and three independent runs, which differed only in starting random seed, were compared. To convert IMa parameter estimates to biologically meaningful values, the parameters were scaled to a substitution rate of $\mu=4 \times 10^{-8}$ substitutions per site per year $(\mathrm{s} / \mathrm{s} / \mathrm{y})$. We also used a lower $\left(\mu=2 \times 10^{-8} \mathrm{~s} /\right.$ $\mathrm{s} / \mathrm{y})$ and an upper $\left(\mu=5.5 \times 10^{-8} \mathrm{~s} / \mathrm{s} / \mathrm{y}\right)$ limit for this conversion, as indicated for the BSP analysis. To estimate generation time $(g)$ we used the equation $g=\alpha+$ $(s /(1-s))$, where $\alpha$ is the age of first reproduction in females and $s$ is the expected adult survival rate [84]. Age at which Montagu's harrier females reach maturity was set at 2 years and estimated adult survival rate at 0.67 , according to published data $[24,85]$. Therefore, we considered a generation time $(g)$ of 4 years to express the output parameters $\left(\theta_{S W}, \theta_{N W}, \theta_{\mathrm{A}}, m_{S W}\right.$, $\left.m_{N W}, t\right)$ in demographic units as follows: effective population size: $N=\theta / 4 \mu g$; number of migrants per generation: $M=\theta \times m / 2 g$; divergence time in years: $T$ $=\operatorname{tg} / 2 \mu$.

\section{Acknowledgements}

Two anonymous reviewers contributed to improving the MS. Samples were kindly provided by R. Limiñana, X. Vázquez, C. Alonso, A. Guerrero, and E. de Prada (Spain), C. Pürckhauer (Senegal), C. Trierweiller (The Netherlands), I. Kunstmuller (Czech Republic), A. Baqri (Pakistan), and B. Van Hecke, T. Printemps (PLO, France), F. Arrias, P. Maigre (PACA, France), S. Paris, JL. Bourrioux, F. Burda (CHAR, France), MF Canevet (AQPY, France), S. Augiron, 
JFB Blanc (PCH, France). We also thank the staff of the collection of DNA and Tissues from the Museo Nacional de Ciencias Naturales (CSIC). Sally Bach reviewed the English text. For research permits we thank the Ministerio de Medio Ambiente, Rural y Marino. This work was supported by JCCM project (Ref: PAC06-0137) and CSIC-MICINN project (Ref: PIE 2010301019), and by Natural Research (fieldwork in Kazakhstan). We performed all the laboratory work, including sequencing, at the Genetics Laboratory of IREC (CSIC-UCLM-JCCM).

\section{Author details}

${ }^{1}$ Instituto de Investigación en Recursos Cinegéticos (IREC) (CSIC-UCLM-JCCM). Ronda de Toledo s/n, E-13005 Ciudad Real, Spain. ${ }^{2}$ Natural Research Ltd, Banchory Business Centre, Burn O'Bennie Road, Banchory, AB31 5ZU, UK. ${ }^{3}$ Estación Experimental de Zonas Áridas (EEZA-CSIC), Ctra. de Sacramento s/ n, La Cañada de San Urbano, 04120 Almería, Spain. ${ }^{4}$ CEBC-CNRS, UPR1934, 79360 Beauvoir sur Niort, France.

\section{Authors' contributions}

JTG conceived and designed the study, collected samples, helped in molecular genetic work, performed analysis and drafted the manuscript. FA participated in the study design, carried out molecular genetic work, performed analysis and helped to draft the manuscript. FM, JT, AS, VB participated in the study design, collected samples and helped to draft the manuscript. BA conceived and designed the study, collected samples and helped to draft the manuscript. All authors read and approved the final manuscript.

Received: 27 June 2011 Accepted: 17 November 2011 Published: 17 November 2011

\section{References}

1. Avise JC: Phylogeography: the history and formation of species Harvard University Press; 2000.

2. Hewitt G: The genetic legacy of the Quaternary ice ages. Nature 2000 405(6789):907-913.

3. Hewitt GM: Some genetic consequences of ice ages, and their role, in divergence and speciation. Biol J Linn Soc 1996, 58(3):247-276.

4. Stewart JR, Lister AM, Barnes I, Dalén L: Refugia revisited: individualistic responses of species in space and time. Proc $R$ Soc Lond B 2010, 277(1682):661.

5. Hewitt GM: Post glacial re-colonization of European biota. Biol J Linn Soc 1999, 68(1 2):87-112.

6. Fedorov V, Goropashnaya A, Jaarola MM, Cook A: Phylogeography of lemmings (Lemmus): no evidence for postglacial colonization of Arctic from the Beringian refugium. Mol Ecol 2003, 12:725-731.

7. Hamill R, Doyle D, Duke E: Spatial patterns of genetic diversity across European subspecies of the mountain hare, Lepus timidus L. Heredity 2006, 97(5):355-365.

8. Hewitt G: Genetic consequences of climatic oscillations in the Quaternary. Philos Trans Roy Soc Lond B 2004, 359(1442):183.

9. García JT, Mañosa S, Morales MB, Ponjoan A, Garcia de la Morena EL, Bota G, Bretagnolle V, Dávila JA: Genetic consequences of interglacial isolation in a steppe bird. Mol Phylogenet Evol 2011, 61:671-676.

10. Li Y-X, Yun-Xianga $Z$, Xiang-Xu $X$ : The composition of three mammal faunas and environmental evolution in the last glacial maximum, Guanzhong area, Shaanxi Province, China. Quatern Int 2011.

11. Sánchez-Marco A: Implications of the avian fauna for paleoecology in the Early Pleistocene of the Iberian Peninsula. J Hum Evol 1999, 37(34):375-388.

12. Sánchez-Marco A: Avian zoogeographical patterns during the Quaternary in the Mediterranean region and paleoclimatic interpretation. Ardeola 2004, 51(1):91-132.

13. García JT, Suárez F, Garza V, Calero-Riestra M, Hernández J, Pérez-Tris J: Genetic and phenotypic variation among geographically isolated populations of the globally threatened Dupont's lark Chersophilus duponti. Mol Phylogenet Evol 2008, 46(1):237-251.

14. Warmuth V, Eriksson A, Bower M, Cañon J, Cothran G, Distl O, GlowatzkiMullis M-L, Hunt H, Luís C, Oom M, et al: European Domestic Horses Originated in Two Holocene Refugia. Plos One 2011, 6(3):e18194.

15. Melo-Ferreira J, Boursot P, Randi E, Kryukov A, Suchentrunk F, Ferrand N, Alves $\mathrm{C}$ : The rise and fall of the mountain hare (Lepus timidus) during
Pleistocene glaciations: expansion and retreat with hybridization in the Iberian Peninsula. Mol Ecol 2007, 16:605-618.

16. Moreno V, Morales M, Traba J: Avoiding over-implementation of agrienvironmental schemes for steppe bird conservation: A species-focused proposal based on expert criteria. J Environ Manage 2010, 91(8):1802-1809.

17. Fuller R, Gregory R, Gibbons D, Marchant J, Wilson J, Baillie S, Carter N: Population declines and range contractions among lowland farmland birds in Britain. Conserv Biol 1995, 9(6):1425-1441.

18. Chamberlain D, Fuller R, Bunce R, Duckworth J, Shrubb M: Changes in the abundance of farmland birds in relation to the timing of agricultural intensification in England and Wales. J Appl Ecol 2000, 37(5):771-788.

19. Siriwardena GM, Crick HQP, Baillic SR, Wilson JD: Agricultural land use and the spatial distribution of granivorous lowland farmland birds. Ecography 2000, 23(6):702-719.

20. Donald PF, Green RE, Heath MF: Agricultural intensification and the collapse of Europe's farmland bird populations. Proc R Soc Lond B 2001, 268(1462):25-29.

21. Ormerod S, Watkinson A: Editors' introduction: birds and agriculture. Appl Ecol 2000, 37(5):699-705.

22. Söderström B, Pärt T: Influence of Landscape Scale on Farmland Birds Breeding in Semi Natural Pastures. Conserv Biol 2000, 14(2):522-533.

23. Clarke R: Montagu's harrier Arlequin Press; 1996.

24. Arroyo B, García JT, Bretagnolle V: Conservation of the Montagu's harrier (Circus pygargus) in agricultural areas. Anim Cons 2002, 5(04):283-290.

25. Arroyo BE, García JT, Bretagnolle V: Circus pygargus Montagu's harrier. BWP Update 2004, 6(1)

26. Ferguson-Lees J, Christie DA, Franklin K, Mead D, Burton P: Raptors of the world. CSIRO; 2001

27. Moreau RE: The Palaearctic-African bird migration systems. Academic Press; 1972.

28. Garcia JT, Arroyo B: Migratory movements of western European Montagu's Harrier Circus pygargus: a review. Bird Study 1998, 45:188-194.

29. Trierweiler C, Koks B, Bairlein F, K-M E, Komdeur J, Dijkstra C: Migratory routes and wintering behavior of NW European Montagu's Harriers revealed by satellite telemetry. J Ornithol 2006, 147(suppl 1):265.

30. Limiñana R, Soutullo V, Urios V, Reig-Ferrer A: Migration and wintering areas of adult Montagu's harriers (Circus pygargus) breeding in Spain. Ornithol 2011

31. Poulakakis N, Antoniou A, Mantziou G, Parmakelis A, Skartsi T, Vasilakis D, Elorriaga J, de la Puente J, Gavashelishvili A, Ghasabyan M, et al: Population structure, diversity, and phylogeography in the nearthreatened Eurasian black vultures Aegypius monachus (Falconiformes; Accipitridae) in Europe: insights from microsatellite and mitochondrial DNA. Biol J Linn Soc 2008, 95:859-872.

32. Martínez-Cruz J, Godoy J, Negro J: Population genetics after fragmentation: the case of the endangered Spanish imperial eagle Aquila adalberti. Mol Ecol 2004, 13:2243-2255.

33. Roques $S$, Negro J: MtDNA genetic diversity and population history of a dwindling raptorial bird, the red kite (Milvus milvus). Biol Cons 2005 126:41-50.

34. Cadahía L, Urios V Negro J: Low mitochondrial DNA diversity in the endangered Bonelli's eagle (Hieraaetus fasciatus) from SW Europe (Iberia) and NW Africa. J Ornithol 2007, 148(1):99-104.

35. Hailer F, Helander B, Folkestad A, Ganusevich S, Garstad S, Hauff P, Koren C, Masterov V, Nygård T, Rudnick J, et al: Phylogeography of the white-tailed eagle, a generalist with large dispersal capacity. J Biogeogr 2007, 34:1193-1206.

36. Godoy J, Negro J, Hiraldo F, Donázar J: Phylogeography, genetic structure and diversity in the endangered bearded vulture (Gypaetus barbatus L.) as revealed by mitochondrial DNA. Mol Ecol 2004, 13:371-390.

37. Pantaléon-Cano J, Errikarta-Imanol Y, Pérez-Obiol R, Roure J: Palynological evidence for vegetational history in semi-arid areas of the western Mediterranean (Almeria, Spain). The Holocene 2003, 13(1):109-119.

38. Gallimore R, Jacob R, Kutzbach J: Coupled atmosphere-ocean-vegetation simulations for modern and mid-Holocene climates: role of extratropical vegetation cover feedbacks. Clim Dynam 2005, 25:755-776.

39. Jalut G, Esteban Amat A, Bonnet L, Gauquelin T, Fontugne M: Holocene climatic changes in the western Mediterranean, from south-east France to south-east Spain. Palaeogeogr Palaeod 2000, 160:255-290. 
40. Mitchell F: How open were European primeval forests? Hypothesis testing using palaeoecological data. J Ecol 2005, 93:168-177.

41. Tiedemann R, Paulus K, Scheer M, al e: Mitochondrial DNA and microsatellite variation in the eider duck (Somateria mollissima) indicate stepwise postglacial colonization of Europe and limited current longdistance dispersal. Mol Ecol 2004, 13:1481-1494.

42. Liebers $D$, De Knijff $P$, Helbig A: The herring gull complex is not a ring species. Proc R Soc Lond B 2004, 271:893-901.

43. Limiñana $R$, Soutullo A, Urios V: Autumn migration of Montagu's Harriers tracked by satellite telemetry. J Ornithol 2007, 148:517-523.

44. Klaassen R, Hake M, Strandberg R, Alerstam T: Geographical and temporal flexibility in the response to crosswinds by migrating raptors. Proc $R$ Soc Lond B 2011, 278:1339-1346.

45. Panuccio M, Agostini N: Spring migration of Pallid (Circus macrourus) and Montagu's harriers (Circus pygargus) in relation to sex and age classes at two watchsites of the central mediterranean. Buteo 2006, 15:3-10.

46. Trierweiler C, Koks B: Montagu's Harrier Circus pygargus. In Living on the edge: Wetlands and birds in a changing Sahel. Edited by: Zwarts L, Bijlsma R, van der Kamp J, Wymenga E. Zeist: KNNV Publishing; 2009:312-327.

47. Limiñana R, García JT, Guerrero A, González JM, Lavedán J, Moreno JD, Muñoz A-R, Palomares LE, Pinilla A, Ros G, et al: Phylopatry and natal dispersal of Montagu's harriers Circus pygargus breeding in Spain: a review of existing data. Eur J Wild Res 2011.

48. Peyron O, Guiot J, Cheddadi R, Tarasov P, Reille R, de Beaulieu J-L, Bottema S, Andrieu V: Climatic reconstruction in Europe for 18,000 yr BP from pollen data. Quaternary Res 1998, 49:183-196.

49. Novenko E, Volkova E, Nosova N, Zuganova I: Late Glacial and Holocene landscape dynamics in the southern taiga zone of East European Plain according to pollen and macrofossil records from the Central Forest State Reserve (Valdai Hills, Russia). Quatern Int 2009, 207:93-103.

50. Klimanov V: Paleoclimatic reconstructions based on the information statistical method. In Late Quaternary Environments of the Soviet Union. Edited by: Velichko A. Minneapolis: University of Minnesota Press; 1984:297-304.

51. Savina S, Khotinsky N: Holocence paleoclimatic reconstructions based on the zonal method. In Late Quaternary Environments of Soviet Union. Edited by: Velichko A. Minneapolis: University of Minnesota Press; 1984:287-296.

52. Zubakov V, Borzenkova I: Global Paleodlimate of Late Cenozoic Amsterdam: Elsevier; 1990

53. Mayewski P, Rohling E, Stager J, Karlèn W, Maasch K, L D, Meyerson E, Gasse F, van Kreveld S, Holmgren K, et al: Holocene climate variability. Quaternary Res 2004, 62:243-255.

54. Tarasov P, Bezrukova E, Karabanov E, Nakagawa T, Wagner M, Kulagina N, Letunova P, Abzaeva A, Granoszewski W, Riedel F: Vegetation and climate dynamics during the Holocene and Eemian interglacials derived from Lake Baikal pollen records. Palaeogeogr Palaeod 2007, 252:440-457.

55. Sorrel P, Popescu S-M, Klotz S, Suc J-P, Oberhänsli H: Climate variability in the Aral Sea basin (Central Asia) during the late Holocene based on vegetation changes. Quaternary Res 2007, 67:357-370.

56. Gasse F, van Campo E: Abrupt post-glacial climatic events in West Asia and North Africa mlonsoon domlains. Earth Planet Sc Lett 1994, 126:435-456

57. Pérez-Obiol R, Jalut G, Juliá R, Pèlachs A, Iriarte M, Otto T, HernándezBeloqui B: Mid-Holocene vegetation and climatic history of the Iberian Peninsula. The Holocene 2011, 21:75-93.

58. Zohary D, Hopf M: Domestication of plants in the old world Oxford: Oxford University Press; 1993.

59. Ruddiman W: The anthropogenic greenhouse era began thousands of years ago. Climate Change 2003, 61:261-293.

60. O'Connor R, Shrubb M: Farming and Birds Cambridge: Cambridge University Press; 1986.

61. Bouma J, Varralyay G, Batjes N: Principal land use changes anticipated in Europe. Agriculture, Ecosystems and Environment 1998, 67:103-119.

62. Alley R, Ágústsdóttir A: The $8 \mathrm{k}$ event: cause and consequences of a major Holocene abrupt climate change. Quaternary Sci Rev 2005 24:1123-1149.

63. Taberlet P, Fumagalli L, Wust-Saucy A, Cosson J: Comparative phylogeography and postglacial colonization routes in Europe. Mol Ecol 1998, 7:453-464
64. Sorenson M, Ast J, Dimcheff D, Yuri T, Mindell D: Primers for a PCR-based approach to mitochondrial genome sequencing in birds and other vertebrates. Mol Phylogenet Evol 1999, 12(2):105-114.

65. Hebert PDN, Stoeckle MY, Zemlak TS, Francis CM: Identification of birds through DNA barcodes. PLoS Biology 2004, 2(10):e312.

66. Hall T: BioEdit: a user-friendly biological sequence alignment editor and analysis program for Windows 95/98/NT. 1999, 1999:95-98.

67. Thompson JD, Higgins DG, Gibson TJ: CLUSTAL W: improving the sensitivity of progressive multiple sequence alignment through sequence weighting, position-specific gap penalties and weight matrix choice. Nucl Acids Res 1994, 22(22):4673-4680.

68. Excoffier L, Laval G, Schneider S: Arlequin (version 3.0): an integrated software package for population genetics data analysis. Evol Bioinf Online 2005, 1:47

69. Tamura K, Nei M: Estimation of the number of nucleotide substitutions in the control region of mitochondrial DNA in humans and chimpanzees. Mol Biol Evol 1993, 10(3):512.

70. Posada D, Crandall K: MODELTEST: testing the model of DNA substitution. Bioinformatics 1998, 14(9):817.

71. Holm S: A simple sequentially rejective multiple test procedure. Scand J Stat 1979, 6(2):65-70

72. Del Hoyo J, Elliott A, Sargatal J, Cabot J: Handbook of the birds of the world: New world vultures to guineafowl. Barcelona: Lynx Editions; 1994

73. Swofford D: PAUP*. Phylogenetic analysis using parsimony ${ }^{*}$ and other methods). Version 4. Sinauer Associates, Sunderland, Massachusetts; 2002

74. Ronquist F, Huelsenbeck JP: MrBayes 3: Bayesian phylogenetic inference under mixed models. Bioinformatics 2003, 19(12):1572-1574.

75. Bandelt $H J$, Forster $P$, Röhl A: Median-joining networks for inferring intraspecific phylogenies. Mol Biol Evol 1999, 16(1):37.

76. Fu YX: Statistical tests of neutrality of mutations against population growth, hitchhiking and background selection. Genetics 1997, 147(2):915.

77. Tajima F: Statistical method for testing the neutral mutation hypothesis by DNA polymorphism. Genetics 1989, 123(3):585.

78. Drummond A, Rambaut A: BEAST v1.4. 2006 [http://beast.bio.ed.ac.uk/.

79. Arbogast B, Drovetski S, Curry R, Boag P, Seutin G, Grant P, Grant R, Anderson D: The origing and diversification of Galapagos Mockingbirds. Evolution 2006, 60(2):370-382

80. Peck D, Congdon B: Reconciling historical processes, population structure in the sooty tern Sterna fuscata. J Avian Biol 2004, 35:327-335.

81. Rambaut A, Drummond A: Tracer v1.4. 2007 [http://beast.bio.ed.ac.uk] Tracer].

82. Hey J, Nielsen R: Multilocus Methods for Estimating Population Sizes, Migration Rates and Divergence Time, With Applications to the Divergence of Drosophila pseudoobscura and D. persimilis. Genetics 2004, 167:747-760

83. Sæther B, Engen S, Møller A, Visser M, Matthysen E, Fiedler W Lambrechts M, Becker P, Brommer J, Dickinson J: Time to extinction of bird populations. Ecology 2005, 86(3):693-700

84. Millon A, Bretagnolle V: Predator population dynamics under a cyclic prey regime: numerical responses, demographic parameters and growth rates. Oikos 2008, 117:1500-1510.

85. del Hoyo J, Elliott A, Sargatal J: Handbook of the birds of the world: New world vultures to guineafowl. Barcelona: Lynx Editions; 19942.

doi:10.1186/1471-2148-11-333

Cite this article as: Garcia et al:: Demographic history, genetic structure and gene flow in a steppe-associated raptor species. BMC Evolutionary Biology 2011 11:333. 